\title{
HEXAMITIASIS IN TORTOISES
}

\section{P. ZWART and E.H.A. TRUYENS*}

Veterinary Pathology, Department of Special Animal Pathology, Utrecht (The Netherlands)

*Present address: Hoofdstraat Oost 63, Wolvega (The Netherlands)

(Received September 19th, 1975)

\section{ABSTRACT}

Zwart, P. and Truyens, E.H.A., 1975. Hexamitiasis in tortoises. Vet. Parasitol., 1: 175-183.

Hexamitiasis was diagnosed in nine chelonians of eight species. The causative organism was identified as Hexamita parva (Alexeieff, 1912). The disease appeared to affect the organs which have an open connection with the intestinal tract.

The kidneys were affected especially. Hexamites could be recognized in collecting ducts and in tubules showing acute and subacute lesions and inflammatory reactions. Parasites were generally absent in tubules revealing signs of regeneration. In the liver, the bile ducts were found to be invaded. Hexamitiasis is a slowly progressing disease causing no specific symptoms.

\section{INTRODUCTION}

Published reports concerning hexamitiasis in reptiles tend to be brief and few in number. Reichenbach-Klinke and Elkan (1965) devote five sentences to Hexamita. Telford (1971) summarizes the subject as follows:"Six or seven genera of flagellates are extremely common in snakes and lizards; none is known to be pathogenic".

The aim of this paper is to present data on a hexamite and its pathogenic properties in chelonians.

\section{MATERIAL AND METHODS}

Nine chelonians in which the diagnosis of hexamitiasis was made, were received from different owners. They belonged to the following species:

Horsefield's tortoise

Tafrail tortoise

Starred tortoise

Brasilian or Hercules tortoise

Malayan box turtle

Ornate box turtle

Tropical American pointed-nosed terrapin

Caspian terrapin (2)
(Testudo horsfieldii)

(T. marginata)

(T. elegans)

(T. carbonaria)

(Cuora amboinensis)

(Terrapene ornata)

(Geoemyda p. punctularia)

(Clemmys caspica leprosa) 
The intestinal contents, kidneys, bile and urine of these reptiles were examined for the presence of hexamites. Smears were prepared, stained with Giemsa's stain and examined under oil immersion. Measurements were made with the aid of a Leitz drawing apparatus and a Leitz Micrometer $2 \mathrm{~mm}$ in 200 parts. In addition, live parasites were studied using phase contrast illumination.

Organs were fixed in $10 \%$ neutral formalin, embedded in paraffin, cut at $7 \mu$ thickness and stained with hemalum-eosin, van Gieson's technique and the periodic acid Schiff (P.A.S.) stain.

\section{RESULTS}

\section{Clinical findings}

All the specimens had been clinically ill for several weeks or months prior to presentation. They failed to thrive, became progressively more apathetic and lost weight. No specific symptoms were recognised.

\section{The parasite}

When examined alive, the parasites usually moved fast and in straight lines, although they were able to alter their direction quickly. In accumulations of solid intestinal contents they often rotated around their long axis and appeared very flexible. In air-dried, stained preparations the parasites were rather pleomorphic, although predominantly egg-shaped. The nuclei were situated at the blunt anterior end and often protruded a little. The blepharoplasts were situated close to the nuclei. Six flagellae originated from the blepharoplasts. Caudal to the nuclei, both rhizostyles could be found traversing the body and terminating shortly before reaching the tapering posterior end and proceeded as two caudal flagellae of unequal length.

The cytoplasm stained only faintly, contained fine granules and occasionally some vacuoles.

In a total of 126 parasites, carrying both caudal and anterior flagellae, the mean body length was $8.03 \mu$; the mean width, $4.79 \mu$. Parasites without posterior flagellae and with only a few anterior ones were, in general, slightly smaller (mean length, $7.79 \mu$; mean width, $4.38 \mu$ ). This was considered to be a fixation artefact. On the basis of these findings, the parasites were identified as Hexamita parva (Alexeieff, 1912).

\section{Pathological findings}

The kidney

The kidneys especially, revealed changes which were variable depending on the degree and duration of the disease. Macroscopically, the kidneys appeared pale in six out of the nine cases. In the G. p. punctularia, one C. c. leprosa 


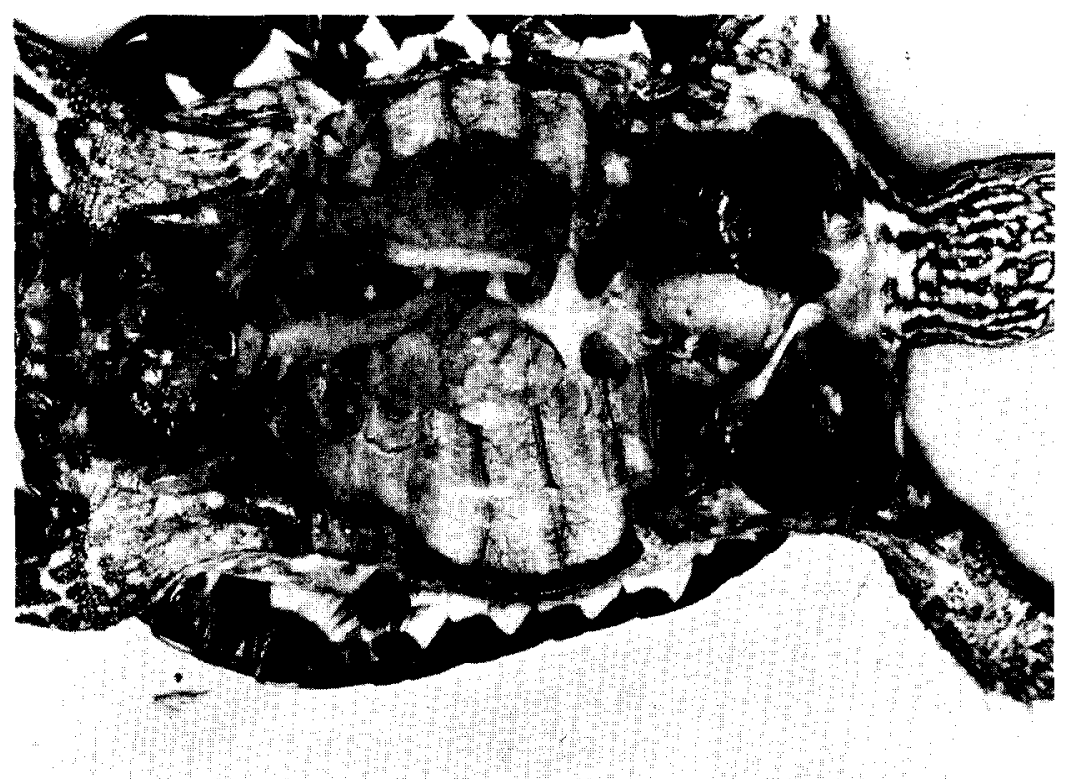

Fig.1. Hexamitiasis in Clemmys c. leprosa caused enlargement of the affected kidneys. (Kidneys dislocated and placed in the body cavity to show their relative size.)
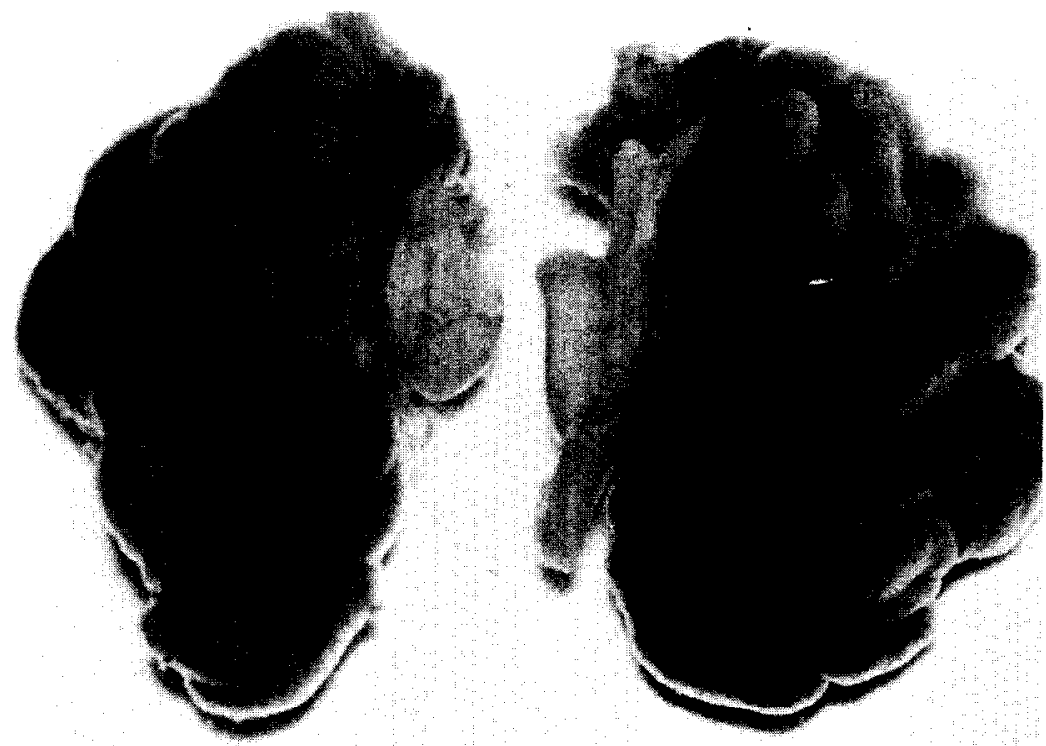

Fig.2. Hexamitiasis in $C$. c. leprosa. The ribbons composed of nephrons bulge distinctly due to dilatation of tubules and inflammatory processes. 
(Figs 1 and 2) and the T. marginata, enlargement of the kidneys was noticeable. The renal tubules were widened to a degree visible to the naked eye in $T$. ornata and $C$. amboinensis. In $T$. ornata the kidneys revealed some induration. Microscopically, changes in the glomeruli were seen in all cases harbouring hexamites in the kidneys. In some cases these changes were restricted to proliferation of the visceral layer of the Bowman's capsule, but in others this had progressed to increased cellularity of the mesangium and thickening of capillary basement membranes. In the proximal segments of tubules, degenerative changes, such as vacuolation of epithelial cells, loss of nuclei and widening of lumina, were present. Hyaline casts were present in one animal. In T. marginata, in addition to these lesions, numerous small gout tophi in glomeruli, tubules and the interstitial tissue were observed.

Lesions attributable to the presence of hexamites were scattered throughout the kidneys. Hexamites were present in the lumina of tubular distal segments (Fig.3) and in collecting ducts. Changes varied from acute to chronic; even within one animal. In acute lesions, parasites were mixed with fragments of epithelial cells and with pseudoeosinophilic granulocytes and lymphocytes within the lumina. The same types of inflammatory cells and slight oedema were also present in the surrounding interstitial tissue. In T. marginata, hexamites were found in collecting ducts and also under the epithelium which was lifted from the basement membrane. The blood vessels of the same animal contained small thrombi adhering to the walls of larger veins. The presence of

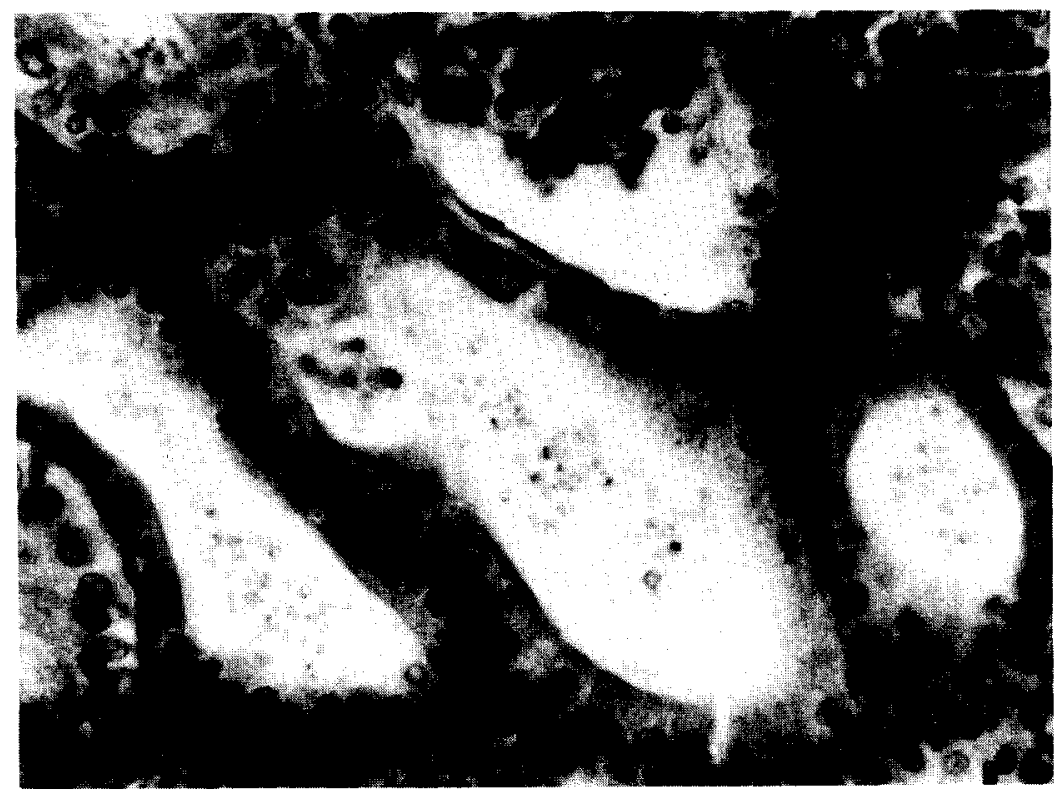

Fig.3. Terrapene ornata. Hexamites present in tubular lumina without distinct alterations at this site (Elastica-Weigert-van Gieson, 250x). 
hexamites near the thrombi was suspected but not definitely confirmed. Changes of a more chronic character were also present, especially in those cases in which gross dilatation of renal tubules had been detected at post mortem examination. Upon microscopic examination, the outlines of the dilated tubules were seen to be irregular and the epithelial cells varied in size and shape (Fig.4), although in general they appeared broader and flatter than normal.

Interstitial roundcell-infiltration and some fibrosis were present (Fig.5) and these changes were especially marked in the case of $T$. ornata. Hexamites were only occasionally found in tubules showing chronic damage.

The presence of hexamites in fresh crush preparations of the kidneys and the location of renal changes is surveyed in Table I.

\section{The urinary bladder}

Hexamites were present in the urine of some animals. In T. horsfieldii, harbouring numerous hexamites, the epithelial cells of the bladder were irregular and hypertrophied.

\section{The liver}

In some cases, hexamites could be found in bile or in fluid collected from the cut surface of the liver. The latter material was specially rich in hexamites in C. amboinensis. In T. carbonaria, the larger bile ducts and the cystic duct were macroscopically thickened and had wide lumina. Microscopically, three

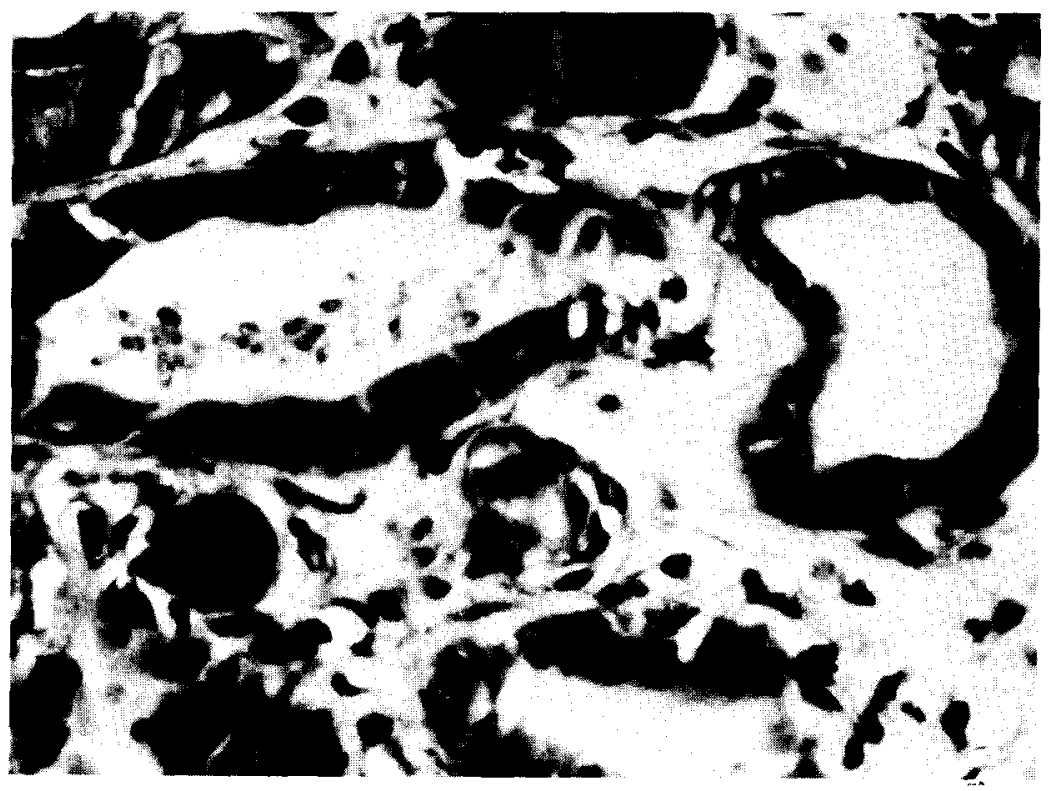

Fig.4. Testudo elegans. Hexamites in subchronically altered tubule. Interstitial oedema and cellular infiltration (hemalum-eosin, 400x). 


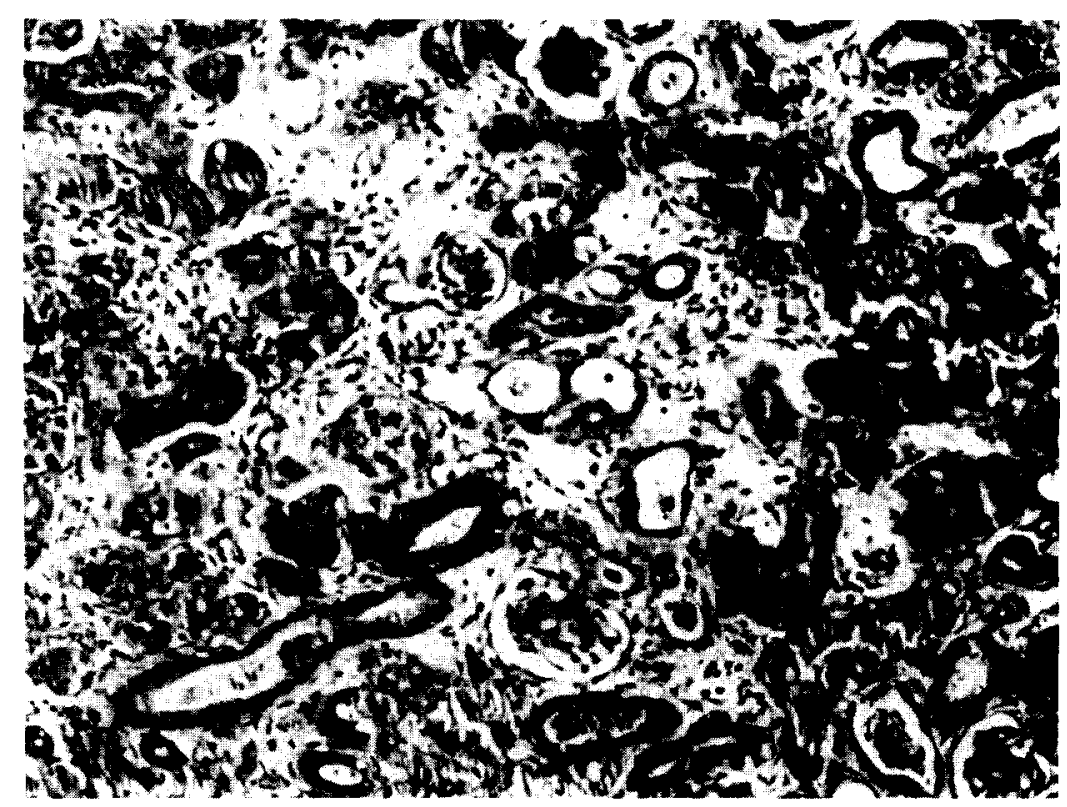

Fig. 5. T. elegans. Subchronic hexamitiasis. Interstitial oedema, cellular infiltration, increase in connective tissue and tubular alterations (hemalum-eosin, 100x).

cases revealed irregularity of bile duct epithelium caused by proliferation of epithelial cells. In two of the animals, the changes were limited to the presence of inflammatory cells in part of the ductal lumina.

In $T$. carbonaria, the main bile ducts were distended and covered with folded epithelium (Fig.6). The proliferating epithelial cells were mostly tall and columnar, showing degenerative or even necrotic changes in some areas. In

\section{TABLE I}

Hexamitiasis in chelonians. Survey of renal changes

\begin{tabular}{|c|c|c|c|c|c|c|}
\hline Tortoise species & $\begin{array}{l}\text { Hexamites } \\
\text { in } \\
\text { kidney }\end{array}$ & $\begin{array}{l}\text { Kidneys } \\
\text { macroscopically } \\
\text { altered }\end{array}$ & $\begin{array}{l}\text { Glomerular } \\
\text { changes }\end{array}$ & $\begin{array}{l}\text { Tubular } \\
\text { changes }\end{array}$ & $\begin{array}{l}\text { Collecting } \\
\text { duct } \\
\text { lesions }\end{array}$ & $\begin{array}{l}\text { Interstitial } \\
\text { lesions }\end{array}$ \\
\hline G. p. punctularia & + & + & - & - & - & + \\
\hline C. caspica leprosa & - & + & - & - & - & - \\
\hline C. c. leprosa & + & + & + & + & ++ & + \\
\hline$T$ marginata & + & + & + & + & ++ & + \\
\hline T. carbonaria & - & - & + & - & + & + \\
\hline$T$. ornata & ++ & + & + & + & + & + \\
\hline$T$. horsfieldii & - & - & + & + & - & + \\
\hline T. amboinensis & + & + & + & + & + & + \\
\hline T. elegans & - & - & + & + & - & + \\
\hline
\end{tabular}




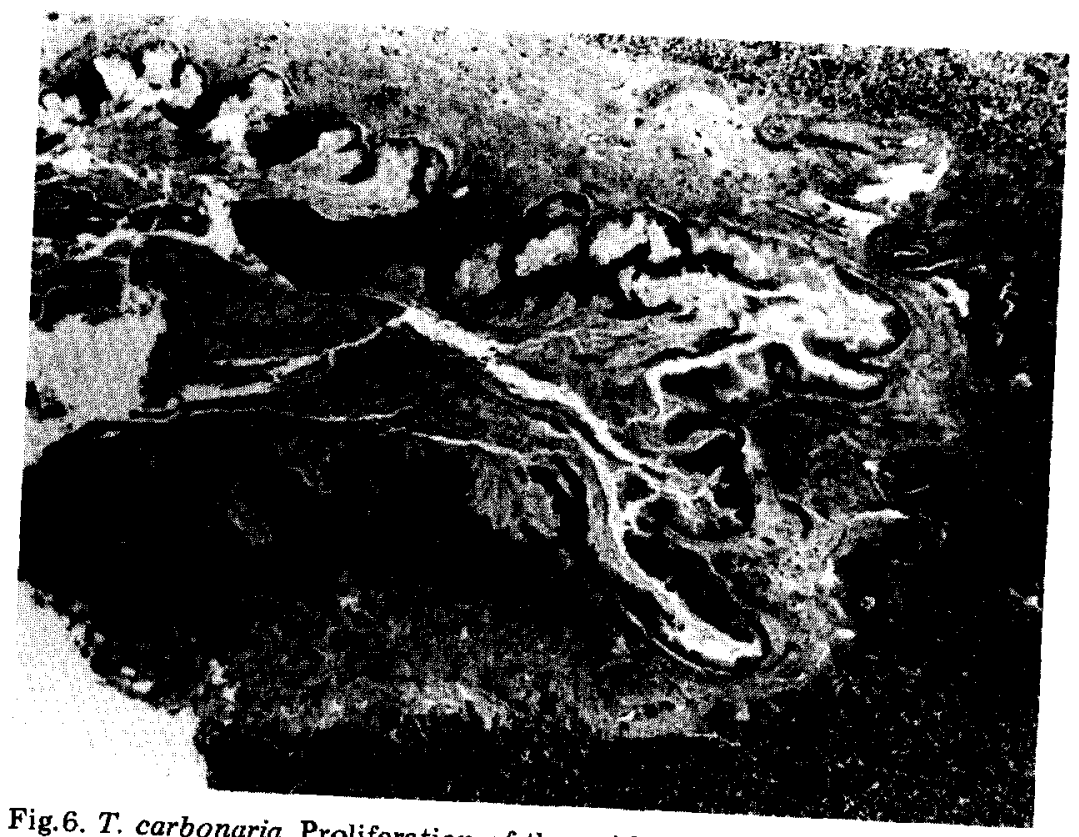

Fig.6. T. carbonaria. Proliferation of the epithelium and lamina propria in the main bile
ducts due to the presence of $H$. parva. these damaged areas, hexamites were present. A periductal fibrosis and
proliferation of arteries had occurred. The process of deposition of connection tissue and accompanying proliferation of pilecess of deposition of connective liver. Locally, the epithelium in these periphe ducts proceeded deep into the was seen to coincide with invasion ofe peripheral ducts was destroyed and this eosinophilic granulocytes, lymphon of inflammatory cells, such as pseudonot observed. Changes in the ductus cysticus of plasma cells; hexamites were those in the main intrahepatic bile ducts.

The intestinal tract

No clinical signs of intestinal dysfunction were seen in any of the cases. The duodenum of $T$. carbonaria only, had focal areas of destruction of epithelial intestine had some irregular pro of hexamites. In four cases, the large infiltration of lymphocytes and preration of the epithelial cells combined with one case were a few hexamite pseudoeosinophilic granulocytes, but in only devoid of surface epithelium. Only the The colon of $T$. carbonaria was nearly mained. Hexamites were recognisable deepest parts of the epithelial folds re-

\section{Other organs}

No specific lesions which could be attributed to hexamites were found in the

heart, lung, spleen, pancreas, adrenals or thyroid gland of any animal.
In a $T$. ornata, the larger collecting tubules of the tertich hexamites without any apparent lesion. 


\section{DISCUSSION}

Grasse (1924) observed numerous parasites restricted to the urinary bladder of pond tortoises (Emys orbicularis L.). Their locomotion was fast and rectilinear. The measurements of living parasites were 6-7 $\mu$ in length and $2.4-4 \mu$ in width. From the figures presented by Grassé, it can be seen that some of his specimens had caudal flagellae of unequal length.

The parasites observed during the present study, were identical with those recorded by Grassé (1924). This parasite was originally named Hexamitus parvus by Alexeieff in 1912 and the species were isolated from a Ceylon tortoise, Geoemyda trijuga (synonym Nicoria trijuga).

In 1917, Alexeieff created the genus Octomastix, correcting silently the lapsus "parvus" to "parva", thus adapting the nomenclature to the original generic designation Hexamita (Dujardin, 1838).

It appears to the authors that infestation with $H$. parva is fairly wide-spread, but that the organisms manifest their pathogenic properties only occasionally. The organs invaded were those which had a direct, open connection with the intestinal tract. The location of lesions in the collecting ducts and distal tubular segments of the kidney tends to suggest an ascending infection originating from the intestine. In the cases studied here, this seems to be a more plausible pathogenic route than by the suggested way of the circulatory system in which hexamites were occasionally found (Reichenbach-Klinke and Elkan, 1965).

It may be stressed here, that the detection of hexamites in a sample of urine does not necessarily imply involvement of the kidneys, since the ureters empty directly into the urodaeum and not into the bladder. Additional evidence with regards to the low pathogenicity of $H$. parva, is the presence of acute lesions in the immediate vicinity of older lesions. The proliferation and hyperplasia of epithelia may be regarded as an incompletely successful attempt at regeneration.

Parasites were present mainly in tubules lined by original epithelium and generally not in those with regenerated epithelium. This may indicate that changes have occurred in the properties of the new cells.

Hexamitiasis in tortoises seems to be a slowly progressing disease, finally leading to death of the animal, mainly due to nephritis.

\section{ACKNOWLEDGEMENT}

The authors thank Mr E.C. Appleby for the critical revision of the manuscript. 


\section{REFERENCES}

Alexeieff, A., 1912. Sur quelques Protistes parasites intestinaux d'une tortue de Ceylan (Nicoria trijuga). Zool. Anz., 40: 97-105.

Alexeieff, A., 1917. Mitochondries et corps basal chez les flagellées. C.R. Soc. Biol., 20: $358-361$.

Grassé, P., 1924. Oxtomastix parvus Alex. Diplozoaire parasite de la cistude d'Europe. C.R. Soc. Biol., 91: 439-442.

Reichenbach-Klinke, H. and Elkan, E., 1965. The principal diseases of lower vertebrates. Academic Press, London, p. 404.

Telford, S.R., 1971. Parasitic diseases of reptiles. J. Am. Vet. Med. Assoc., 159: 16441652 . 